\title{
What Professional Librarians Expect from Administrators: Another Librarian's View
}

\section{Deborah Fink}

This article is a nonadministrator's response to Cheryl A. Price's contribution. Effective administration is described in terms of leadership, clarity, and the actualization of values. The thirteen factors presented by Price are analyzed from that perspective.

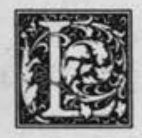

ike most nonadministrators, I am certain that if I were managing, I would do things differently, which is to say better. However, I must hypothesize that the perspective gained when one ascends to the heights of administration makes it clear to the manager, though obfuscated to others, why certain choices are made. Being asked to respond to the Price article has provided me the opportunity to articulate my perceptions, unaffected by direct experience or exhaustive research, of what constitutes effective leadership.

Before reading the article, I brainstormed to release my own thoughts about what an effective administrator is. Upon reading the article I discovered that we are essentially in agreement. We differ primarily in emphasis and in the details of implementation. I will proceed, then, by setting forth my own view and analyzing Price's thirteen factors from that perspective.

Library administration is a specialization-just as bibliographic instruction, serials cataloging, and rare books are areas of specialization-that practitioners must keep up with and advance in. The effective administrator is conversant in an array of managerial theories and styles but synthesizes an individual approach and continuously develops and refines that approach, consciously selecting and applying the particular technique that seems most useful in a situation.

Because people and organizations are complex and multidimensional, an eclectic approach to management is the most viable. Managers do well, therefore, to draw not only from management theory but also from psychology, sociology, communication, anthropology, political science, women's studies, the human potential movement, learning theory, and problem-solving skills, remaining open to potentially useful techniques wherever they may be discovered.

Ideally, the administrator will discern the most effective managerial structure for each direct line manager and develop relationships that vary but are individually conducive to unique needs and styles. The process is organic, for the administrator grows, changes, and evolves while drawing upon new information and experience. Effective administrators will actively engage in continuous analysis and selfevaluation. Individuals who are receptive and willing to experiment and take risks will create a dynamic process.

Deborah Fink is Instructional Services Librarian at the University of Colorado, Boulder, Colorado 80309. The author wishes to acknowledge the insightful assistance of Bartholemew Logue Greenberg. 
Key attributes an administrator must develop are leadership, clarity and actualization of values. The primary function of administration is leadership, which includes setting direction, fostering positive attitudes, and making choices. Organizational purpose and direction are typically mapped out in mission statements and goals as well as in an organizational chart.

To be effective the overall mission and goals would emerge from and provide structure to more specific unit goals and objectives. The relationship parallels the way a well-wrought thesis statement and outline reflect each other. Administrators have the perspective from which to look for congruence of institutional and departmental goals and objectives. A careful orchestration of the goal-setting process will also provide for the integration of individual and institutional needs.

Most individuals in service occupations seek personal satisfaction through commitment to social values. While a mission and goals are fairly standard and may be taken for granted on the day-to-day level, such operating guidelines are most valid when they emanate from a clear, evolving vision. Administrators have the opportunity to express the role of the library in the ideal, noting its relationship to, and potential to serve, its community.

Policies and procedures must also be clearly stated and should exist to support the goals and mission. The effective administrator should be familiar with and supportive of all policies, but the development and maintenance of work flow and procedures will be delegated to line managers. The effective administrator is also cognizant of and able to walk the fine line between providing general direction and allowing autonomy.

Another function of administration is to foster positive attitudes toward the library both internally and externally. Administrators will spend considerable time outside the library promoting, lobbying, and generating support, both fiscal and attitudinal. Political savvy must be honed.

Equally important is time spent inside the library. An open-door policy will not demonstrate receptivity as convincingly as an "open encounter" approach, in which the manager engages with personnel where they live-in offices and at service points. Only from such a firsthand, experiential practice can an administrator know the working reality of the organization. The attitude perceived, however, must not be one of intrusion or judgment but of shared interest and concern.

"... the open encounter will balance the administrator's concern with the big picture-the institution, the mission, the budget-with a focus on employees as the people who bring the mission to life with their actions on the job."

The open encounter is also valuable because as one moves higher in the organization and the perspective widens, it is critical to retain the ability to focus on and relate to the details that recede. In addition, the open encounter will balance the administrator's concern with the big picture-the institution, the mission, the budget-with a focus on employees as the people who bring the mission to life with their actions on the job. The administrator can then return to the outside world with the capacity to feel and thereby better articulate needs.

From such forays into the front lines the administrator will be able to determine both the public image and the self-image of the library, which is an indication of employee morale. Organizational morale is the manager's responsibility. The ultimate measure of leadership is a sense of shared purpose and team effort. In fact, this discussion points to the creation of high morale and positive self-image because a library's positive self-image will translate into the public's positive experience.

A sense of team effort is engendered in subordinates in part through participation in decision making. Where choices are made over a period of time, standard procedures for equipment requests and budget or personnel allocations can offer 
opportunities to express needs. Such opportunities will provide maximum benefit when the final decision-making process is explained, however. Managers must decide when it will be worthwhile to extend the decision-making process and to whom, but it is more satisfying to participate when the entire process is revealed.

The second attribute of effective administration is clarity. Not only should all forms of communication be characterized by this, but a variety of communication channels needs be established and maintained. Communication flow requires channels for both downward and upward movement. Effective administrators will provide direction and information, as well as solicit information, both factual and affective. The sense of team effort is further engendered when personnel feel informed. Certainly in a profession that specializes in acquiring and providing information, these functions should be a personnel priority as well.

Two areas where clarity is especially critical are in setting job responsibilities and standards and in providing feedback. Job descriptions should be provided during hiring and reviewed regularly as a part of the evaluation process. Standards for job performance must be set forth along with criteria for assessment. Just as important as a routine, standardized evaluation process are continuous, constructive feedback, acknowledgment, and recognition. The combination of formal and informal responses can be used to create an atmosphere of open evaluation in the spirit of working together to best accomplish individual and mutual goals. Recognition and appreciation are imperative for high morale.

The third attribute of effective leadership is the actualization of values, especially fairness, excellence, and service. The ideal leader is above all a model. Effective administrators must be clear about their values and act in accordance. Two areas where fairness can be demonstrated are in salaries and affirmative action.

As members of a female-dominated profession, librarians have comparatively depressed salaries. This situation should not be compounded by internal salary inequi- ties, especially gender-based discrepancies. ARL salary surveys indicate that female librarians are paid less than male librarians, who hold managerial positions in numbers that exceed their percentage in the profession. Administrators must monitor internal salary equity, provide discrimination restitution where problems are evident, and actively seek to hire and promote both women and minorities.

Effective administrators will also make a commitment to excellence. Excellence is not easily described, but it embraces high standards, definition and achievement of results, and the ongoing adjustment of priorities.

Professional development is integral to developing these qualities. Because effective administrators are dynamically engaged in their own professional development, they should actively encourage and provide for the professional development of their personnel on a variety of levels.

Library functions are typically designated as "services" -technical services, public services, instructional services. Administration will succeed most when approached as an internal support service providing maintenance (budget, staffing, equipment), overall environment (both physical and affective), and positive support (constructive criticism, encouragement, and recognition). The service attitude is manifested in a desire to make it possible for, or to empower, personnel to do their best by providing direction, context, and support.

Any thoughtful person who has focused attention on management or leadership can enumerate qualities considered most essential for effectiveness. What Price attempts is a translation of such qualities into tangible factors shaping working conditions. The factors themselves are clearly desirable, if not essential. However, many of the arguments posed for each factor are flawed in their development.

Price describes a stable environment as one in which role ambiguity and workrelated stress are minimized. She relates role clarity to job satisfaction but does not discuss stress. The need for clarity surpasses clearly defined responsibilities and permeates all aspects of administration, as 
discussed above. Price fails to be clear herself about how an administrator achieves clarity of communication, other than through consistent behavior, although the two do not necessarily equate.

Her later discussion of clear administrative lines dissolves into a confusing discussion of management style, including the need for upward communication. One of the leadership functions of an administrator is the establishment of an organizational structure, but Price has not made a clear connection between structure and style. She notes later that an administrator should seek input from librarians for decision sharing but does not mention the need for downward communication.

Feeling informed about what is going on and why goes a long way toward creating a feeling of stability. Established, routine channels of communication, such as regular newsletters, meetings, and encounters, are mechanisms that can enhance stability through information and participation.

Price maintains that an administrator "has the obligation to ... match qualified people with appropriate positions," and she equates this with meaning in the position. Matching people and positions should be accomplished through hiring, including written job descriptions and forthrightness in discussing expectations. The administrator must insist that an appropriate search process be maintained through library procedures as well as through institutional support.

\section{"Meaning in the job transcends matched skills and duties. . . ."}

Meaning in the job transcends matched skills and duties, however. Appropriate and challenging responsibilities, delineated in a clear job description, should be combined with the flexibility described by Price. Meaning is also derived from an environment that maximizes congruence between personal and organizational values.

Although I agree that opportunities for professional growth and creative development are essential, I question whether it is realistic to expect that when a "professional has interests in areas where he or she does not have skills, it may behoove the administrator to provide an opportunity for that growth." Rather, I place professional and peripheral development in the broader context of excellence as an overall value. Every employee should be empowered to achieve personal excellence as they are stimulated to achieve organizational excellence.

Price claims that "fear is the worst element that can be unleashed in an organization," and that "an administrator must inspire trust." She then advocates participative management but does not explain how that particular style will alleviate fear or engender trust. Rather, she moves directly to a discussion of where participative management is not appropriate. Participative management is a preferred approach in many contexts, but, as I maintain, the effective administrator will avoid identifying with a single style in order to dynamically develop and draw upon an array of approaches.

Leadership is included in Price's list of thirteen factors, but she argues for this quality only in the context of where participative management leaves off. Leadership is a complex, subtle, and pervasive administrative attribute. It must be manifested within and without the library in the fulfillment of responsibilities ranging from developing mission statements to modeling values.

Price is clear about the dangers of autocracy and the value of the feeling of prestige that involvement can create. Once again, however, she provides only passing reference to one of her thirteen factors-supervisory support. In my own analysis, I defined administration as a support service. Providing such a service is no less than actualizing the service ethic upon which our profession is based.

I agree with Price that administrators should "fight to upgrade . . . employment conditions and salaries," making claims for comparable worth where appropriate. The external administrative function is to generate both fiscal and atti- 
tudinal support for the library. While administrators may face overwhelming obstacles in this regard, autonomy and flexibility can usually be exercised with the internal distribution of salary monies and promotional opportunities. In this regard the manager will actualize the value of fairness.

Administrators may again be faced with overwhelming obstacles in their attempt to provide a healthful environment. At the very least, managers can identify problem areas and make whatever adjustments are possible without major cost or remodeling commitments. Assessment procedures by staff or outside consultants can facilitate this process.

Price's thirteen qualities are useful for assessing administrative effectiveness. The attributes I identified are similar, though organized and prioritized differently. We are in complete agreement, however, that "good management is a team effort." No doubt, administrators give just as much thought to what they expect from librarians in order to create an effective team. 